\title{
Impact of gas supply system development scenarios on natural gas demand in the Baikal region
}

Alexander Izhbuldin", Melentiev Energy Systems Institute of Siberian Branch of the Russian Academy of Sciences, Irkutsk, Russia

\begin{abstract}
The paper presents a methodology and results of studies on assessment of natural gas demand, its competitive price, gas cost and potential gas demand for different scenarios of gas supply system development in the Baikal region. The options of gas pipeline systems of different capacities from the Kovykta gas-condensate field and the nonpipeline gas supply systems are focused on.
\end{abstract}

\section{Introduction}

The problem of gas supply to the entities of the Baikal region, which includes Irkutsk Region, Republic of Buryatia and Trans-Baikal Territory, has a long history. This problem emerged above 20 years ago and was stipulated by additional exploration and preparation for commercial operation of the Kovykta gas-condensate field (GCF), the license for it belonged to OJSC "RUSIA Petroleum". The International feasibility study of the gas pipeline project Russia - China - South Korea with its route Kovykta GCF - Sayansk Irkutsk - Ulan-Ude - Zabaikalsk in Russia and further to China was prepared in 2003. When realized, the project could lay the groundwork for natural gas involvement in the fuel balance of the entities of the Baikal region, as far as the planned route passed through the populated and developed areas. Subsequently, all possible development options of gas supply systems in the Baikal region were studied. The paper classifies the results of studies carried out at Melentiev Energy Systems Institute, SB RAS to assess natural gas demand, its competitive prices, natural gas cost and demand for different development scenarios of gas supply systems.

\section{Methodology of the study}

Initially the studies on the prospects for using gas in the Baikal region were limited to the assessment of natural gas volumes to replace used fuel and to the calculation of competitive prices. In doing so, account was taken of potential consumers along the planned export gas pipeline Kovykta GCF - Sayansk - Irkutsk - Ulan-Ude - Zabaikalsk (the red line in Fig. 2). The estimates of natural gas volumes and competitive prices included changes in equipment characteristics, decrease of operating costs, e. g., owing to

\footnotetext{
* Corresponding author: izhbuldin@isem.irk.ru
} 
removal of the fuel handling system and the coal storehouse at the boiler plant because of its switching to gas. The obtained results were displayed on the graph, where the consumption volume was plotted against the horizontal axis and the competitive price against the vertical axis (Fig. 1).

Henceforth, as far as the export project suggested in the International feasibility study of 2003 was stopped, the alternative scenarios of gas supply system development in the Baikal region were offered for discussion.

The scenarios involve the construction of different facilities: pipeline systems of different diameters and respectively, of different capacity or LNG plants (liquefied natural gas) and corresponding logistic capacities for LNG delivery to consumers and its storage. As any production facilities, the gas supply systems are characterized by a set of technical and economic indicators, the gas cost being the most important and sensitive indicator for a consumer.

The gas cost estimate at the inlet to the regional gas pipeline system was chosen as such an indicator in the studies.

After the gas consumption volumes and competitive prices, and also the gas cost for different gas supply scenarios were determined, it became possible to assess the gas demand. To be competitive, the consumer's competitive price in the scenarios should be higher than the gas cost.

Eventually, the natural gas demand for different gas supply scenarios was determined for the entities of the Baikal region.

\section{Potential of using gas in the Baikal region}

Potential gas consumers in the Baikal region are: households (for cooking and heating), boiler plants, thermal power plants, industrial consumers. Thereby, an energy source, which can compete with natural gas, is assigned to each consumer. Such energy sources are electrical energy, coal and fuel wood (with the corresponding prices in each entity) for households, coal and fuel oil for boiler plants and power plants, primarily fuel oil for industrial consumers. Chemical factories of the Irkutsk Region should be treated separately, as they could use natural gas as a feedstock.

The potential natural gas demand by existing consumers in the Baikal region amounts to about 7 billion $\mathrm{m}^{3} /$ year (Fig. 1). Almost half of this volume is accounted for thermal power plants.

The results of studies carried out at Melentiev Energy Systems Institute have showed that replacement of the used energy sources by natural gas is economically sound for households, boiler plants with a capacity of about $10-15 \mathrm{Gcal} / \mathrm{h}$, and industrial furnaces on fuel oil. Substitution of coal at operating cogeneration plants is not economically attractive because of a relatively low coal price in the region $[1,2,3]$. Hence, the real gas consumption by the existing consumers in the Baikal region is about 3.6 billion $\mathrm{m}^{3} /$ year.

Consumers of the central ecological area of the Baikal natural territory with tight environmental restrictions should be considered separately. The potential gas demand there is about 100 million $\mathrm{m}^{3} /$ year. Substitution of used coal for natural gas would considerably decrease the anthropogenic impact on the geo-ecology of the central ecological area of the Baikal natural territory. 


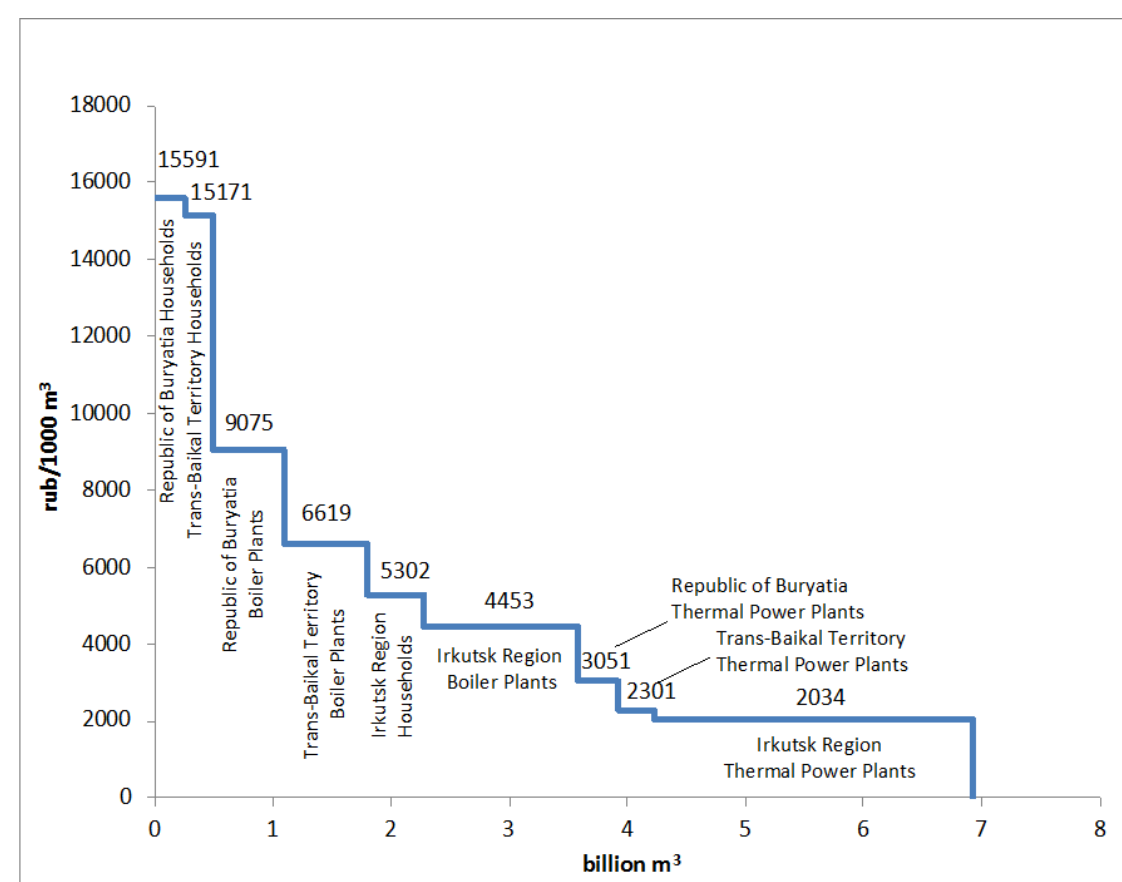

Fig. 1. Potential natural gas demand and competitive gas prices for consumers of the Baikal region

\section{Scenarios of gas supply system development}

Liquefied petroleum gas (LPG) that are the products of petroleum refining are used at present for gas supply to consumers of the Baikal region. In 2018 the LPG prices (equivalent to $1000 \mathrm{~m}^{3}$ of natural gas) were 23.0 thousand RUB/1000 $\mathrm{m}^{3}$ for consumers of the Irkutsk Region, 19.4 thousand RUB/1000 $\mathrm{m}^{3}$ for the Republic of Buryatia, 29.3 thousand RUB/1000 $\mathrm{m}^{3}$ for the Trans-Baikal Territory (Table 1).

The gas supply systems can develop in two ways: non-pipeline gas supply (liquefied gas) or gas supply by pipelines.

Using LPG will not apparently increase gas consumption, or gain effects from its use by consumers because of their high prices in comparison with the other energy sources.

The non-pipeline gas supply is possible by using liquefied natural gas (LNG). The average LNG price including the costs on creation of the infrastructure for LNG production, storage, transmission and regasification is estimated at 15.0-17.0 thousand RUB $/ 1000^{3}$ for consumers of the Irkutsk Region, 18.0-20.0 thousand RUB/1000 $\mathrm{m}^{3}$ for consumers of the Republic of Buryatia, 20.0-22.0 thousand RUB/1000 $\mathrm{m}^{3}$ for consumers of the Trans-Baikal Territory. Such prices are comparable with the prices of LPG supplied to consumers today. It means that the LNG supplies will not increase the gas demand. Therefore, creation of the corresponding infrastructure for LNG storage, transmission and regasification is a doubtful project from the economic standpoint.

Piped natural gas supply is economically more attractive for consumers.

There are two possible routes for gas transmission from the Kovykta GCF in the eastern direction: the so-called "southern" and "northern" routes (options) [1]. The northern option called "Sila Sibiri" provided for laying of the gas transmission system in the common corridor with the ESPO oil pipeline and possible connection of the Kovykta and Chayanda gas fields. It should be noted that on the leg from the field to the territory of the Amur 
Region the northern route would pass through the undeveloped areas: the population along the pipeline route to the Amur Region numbers 159 thousand people (Fig. 2).

The southern option provided for the creation of the gas transmission system from the Kovykta GCF to the border of China in Zabaikalsk. In this case the route would pass through the populated and developed territories: the population along the pipeline route to the border with China numbers 1635 thousand people. Such an option allowed the gas supply to consumers of the Baikal region to be started and the gas export to China and Mongolia to be arranged [2, 3, 4].

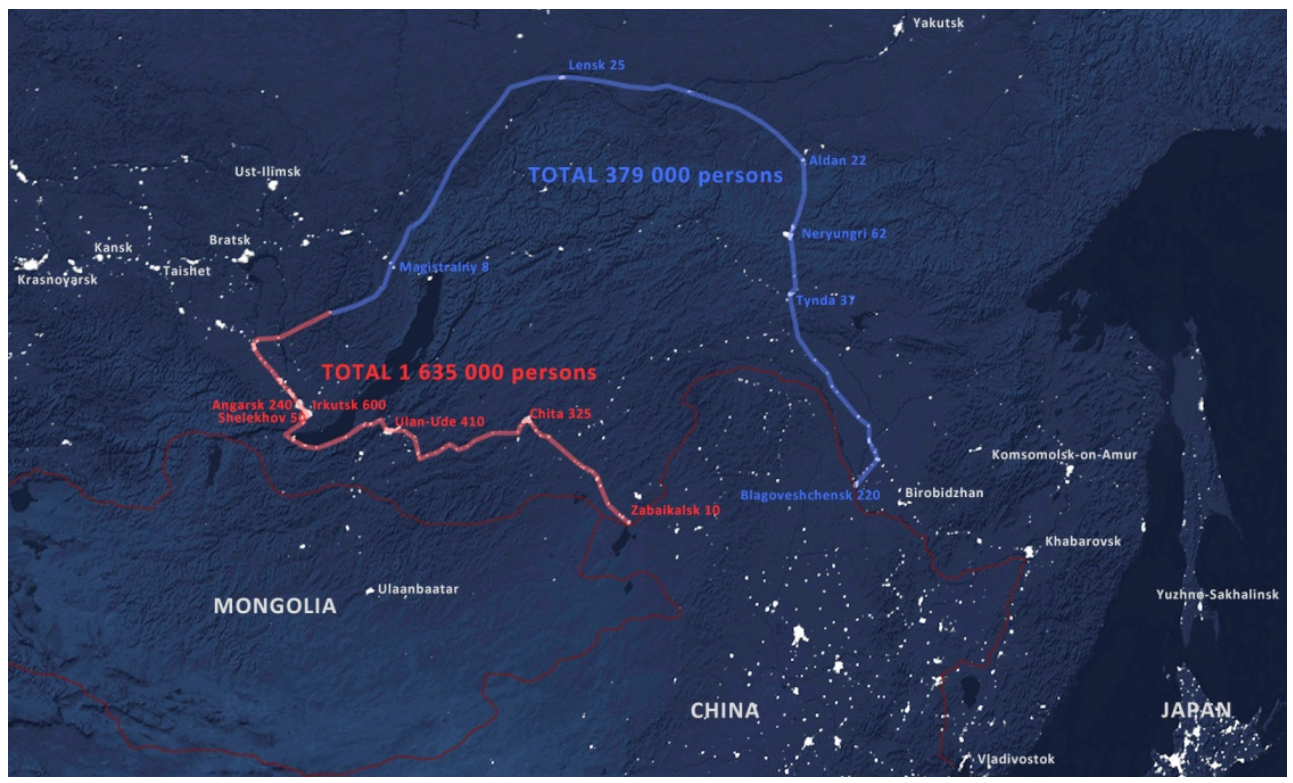

Fig. 2. Population number along the gas pipeline routes

According to the southern option, in the case of the export gas pipeline with a large diameter the average gas cost without the tariff of gas transmission by distribution networks is estimated at 3.1-4.0 thousand $\mathrm{RUB} / 1000 \mathrm{~m}^{3}$ for consumers of the Irkutsk Region, 3.64.8 thousand RUB/1000 $\mathrm{m}^{3}$ for consumers of the Republic of Buryatia, 4.1-5.7 thousand $\mathrm{RUB} / 1000 \mathrm{~m}^{3}$ for consumers of the Trans-Baikal Territory (Table 1) [5].

Table 1. Gas cost for different scenarios of gas supply to consumers of the Baikal region, thousand RUB $/ 1000 \mathrm{~m}^{3}$ (without VAT)

\begin{tabular}{|l|c|c|c|c|c|}
\hline \multirow{2}{*}{ RF entity } & \multicolumn{5}{|c|}{ Scenario } \\
\cline { 2 - 6 } & \multicolumn{2}{|c|}{ No pipelines } & \multicolumn{3}{c|}{ Pipelines } \\
\cline { 2 - 6 } & LPG & LNG & $\begin{array}{c}\text { Export gas } \\
\text { pipeline from } \\
\text { Kovykta GCF }\end{array}$ & $\begin{array}{c}\text { Local gas } \\
\text { pipeline from } \\
\text { Kovykta GCF }\end{array}$ & $\begin{array}{c}\text { Local gas } \\
\text { pipeline } \\
\text { from "Sila } \\
\text { Sibiri" }\end{array}$ \\
\hline $\begin{array}{l}\text { Irkutsk Region } \\
\text { Republic of } \\
\text { Buryatia }\end{array}$ & 23.0 & $15.0-17.0$ & $3.1-4.0$ & $3.6-4.8$ & - \\
\hline $\begin{array}{l}\text { Trans-Baikal } \\
\text { Territory }\end{array}$ & 29.3 & $18.0-20.0$ & $3.6-4.8$ & $5.1-7.3$ & $10.8-16.7$ \\
\hline
\end{tabular}


If gas supply to the Baikal region is considered as an individual regional project, it will be necessary to construct a local system of pipelines for transmission of the required gas volumes. Based on the forecast volumes of natural gas demand in the Baikal region a 700 $\mathrm{mm}$ gas pipeline must be laid through the territory of the Irkutsk Region, further a $500 \mathrm{~mm}$ pipeline through the Republic of Buryatia, a $300 \mathrm{~mm}$ pipeline from the Republic of Buryatia to the Trans-Baikal Territory. If the regional project on gas transmission system development is implemented, the average gas cost without the tariff of gas transmission by distribution networks is estimated at 3.6-4.8 thousand RUB/1000 $\mathrm{m}^{3}$ for consumers of the Irkutsk Region, $5.1-7.3$ thousand RUB/1000 $\mathrm{m}^{3}$ for consumers of the Republic of Buryatia, 7.9-11.9 thousand RUB/1000 $\mathrm{m}^{3}$ for consumers of the Trans-Baikal Territory

An option of laying the pipeline branch from the export gas transmission system "Sila Sibiri" along the route Skovorodino - Chita - Ulan-Ude was also studied in addition to those described. According to the tentative assessments the average gas cost without the tariff of gas transmission by distribution networks is estimated at 8.1-12.2 thousand RUB $/ 1000 \mathrm{~m}^{3}$ for consumers of the Trans-Baikal Territory, 10.8-16.7 thousand RUB/1000 $\mathrm{m}^{3}$ for consumers of the Republic of Buryatia (Table 1), which is more expensive than the laying of the pipeline of mean and small diameters from the Kovykta GCF.

\section{Gas market in the entities of the Baikal region}

The estimates of gas demand, competitive prices and gas cost for different scenarios of gas supply system development in the Irkutsk Region, the Republic of Buryatia and the Trans-Baikal Territory are plotted in Figs. 3-5. The presented plots can be interpreted as a demand line (estimates of consumption volumes and competitive prices) and supply lines (gas cost for different scenarios of gas supply system development). The projections of intersections of the demand line with the supply lines on the horizontal axis indicate the gas demand in the region for the corresponding scenario of gas supply system development.

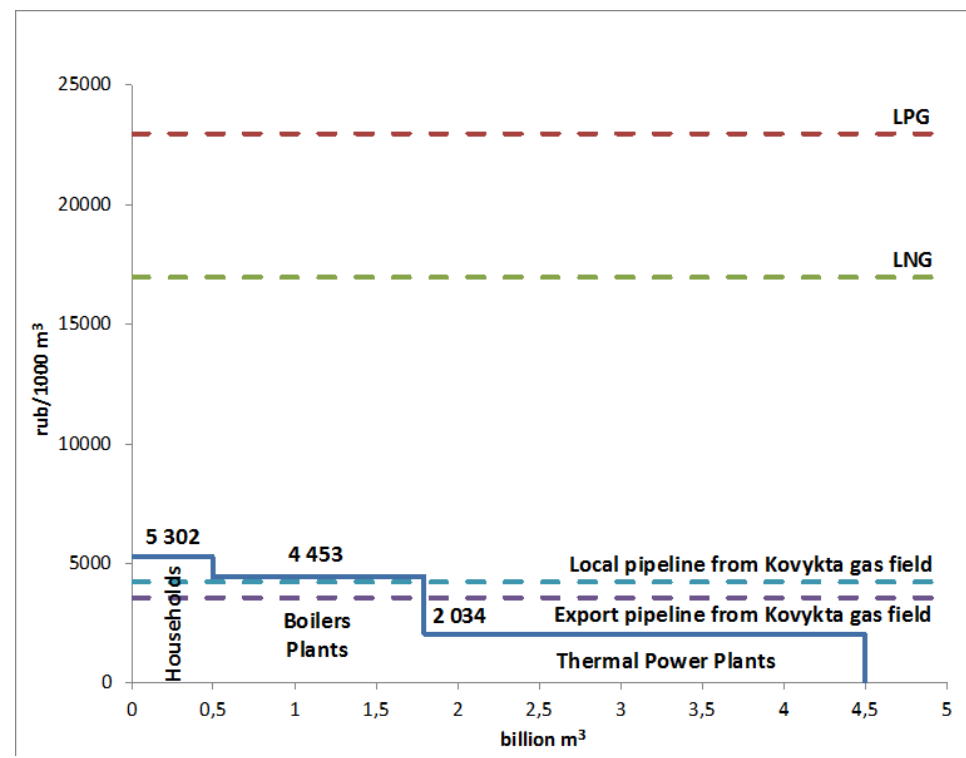

Fig. 3. Gas market in the Irkutsk Region 


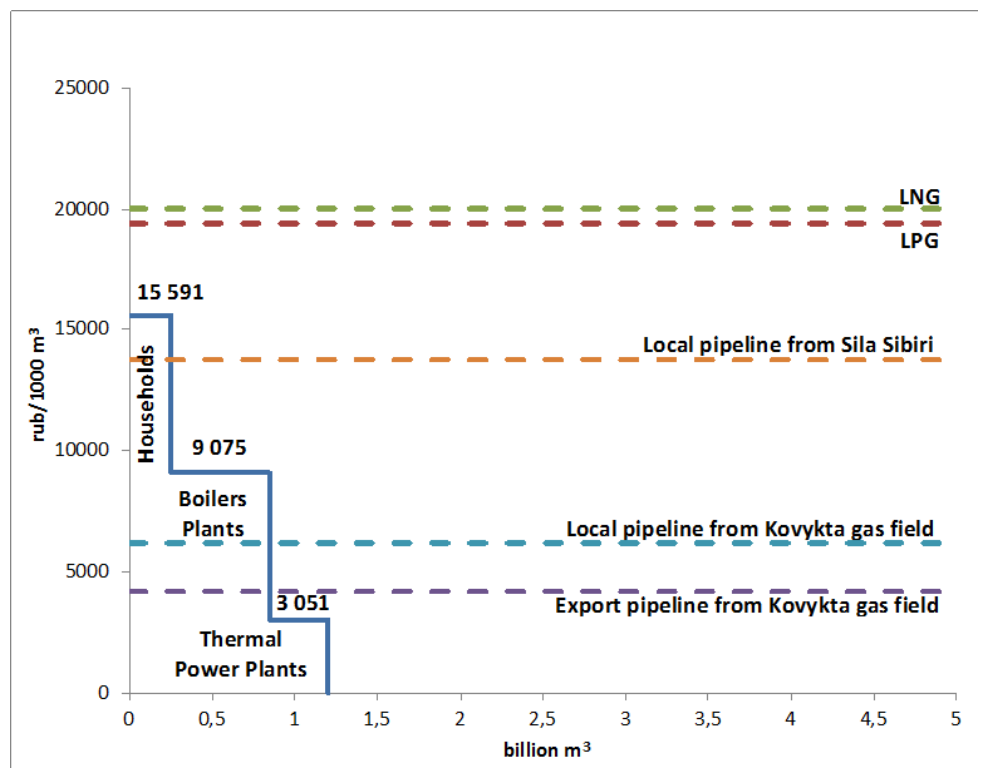

Fig. 4. Gas market in the Republic of Buryatia

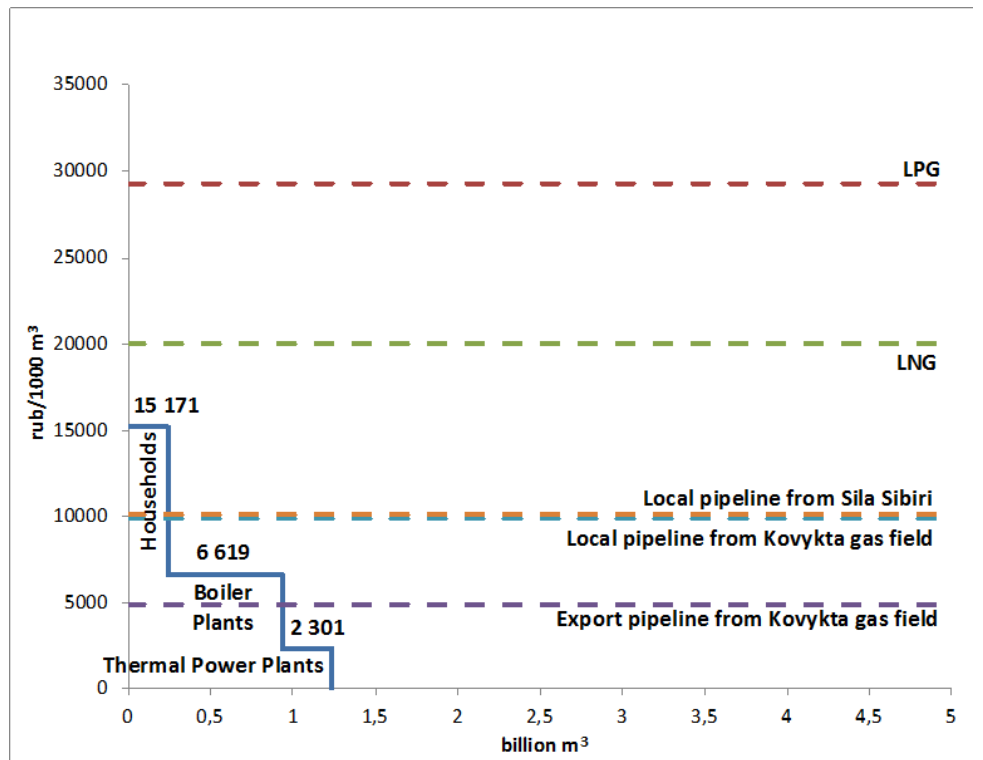

Fig. 5. Gas market in the Trans-Baikal Territory

The analysis of the plots shows that implementation of the export gas pipeline will create attractive conditions for using gas by households and boiler plants in all entities of the Baikal region. Implementation of the regional gas pipeline from the Kovykta GCF is also attractive for the Irkutsk Region and the Republic of Buryatia. In the Trans-Baikal Territory implementation of this scenario will be effective only for households. The option with construction of the regional gas pipeline branch from the gas transmission system "Sila Sibiri" can make the gas competitive only for population of the Republic of Buryatia and the Trans-Baikal Territory. In the scenarios of development of LNG and LPG supply systems the conditions for households are adverse due to the noncompetitive gas cost. 
Thus, the potential natural gas demand in the Baikal region will amount to 3.6 billion $\mathrm{m}^{3} /$ year with implementation of the export gas pipeline option from the Kovykta GCF, 2.9 billion $\mathrm{m}^{3} /$ year with implementation of the regional gas pipeline option along the same route, 0.5 billion $\mathrm{m}^{3} /$ year with the option of construction of the regional gas pipeline branch from the gas transmission system "Sila Sibiri" (Table 2).

Table 2. Natural gas demand in the Baikal region for different scenarios of gas supply to consumers, billion $\mathrm{m}^{3} /$ year

\begin{tabular}{|c|c|c|c|c|c|}
\hline \multirow{2}{*}{ RF entity } & \multicolumn{5}{|c|}{ Scenario } \\
\cline { 2 - 6 } & \multicolumn{2}{|c|}{ No pipelines } & \multicolumn{3}{c|}{ Pipelines } \\
\cline { 2 - 6 } & LPG & LNG & $\begin{array}{c}\text { Export gas } \\
\text { pipeline from } \\
\text { Kovykta GCF }\end{array}$ & $\begin{array}{c}\text { Local gas } \\
\text { pipeline from } \\
\text { Kovykta GCF }\end{array}$ & $\begin{array}{c}\text { Local gas } \\
\text { pipeline } \\
\text { from “Sila } \\
\text { Sibiri” }\end{array}$ \\
\hline Irkutsk Region & 0.0 & 0.0 & 1.8 & 1.8 & - \\
\hline $\begin{array}{c}\text { Republic of } \\
\text { Buryatia }\end{array}$ & 0.0 & 0.0 & 0.9 & 0.9 & 0.3 \\
\hline $\begin{array}{c}\text { Trans-Baikal } \\
\text { Territory }\end{array}$ & 0.0 & 0.0 & 0.9 & 0.2 & 0.2 \\
\hline Total & 0.0 & 0.0 & 3.6 & 2.9 & 0.5 \\
\hline
\end{tabular}

\section{Conclusions}

The results of studies show that the export gas pipeline from the Kovykta GCF according to the "southern" option would create the groundwork for full satisfaction of the potential gas demand in the Baikal region. The regional gas pipeline project will make it possible to meet the potential natural gas demand by $80 \%$. The natural gas supplied by the regional pipeline branch from the gas transmission system "Sila Sibiri" can be attractive only for population of the Trans-Baikal Territory and the Republic of Buryatia in the volume of no more than 0.5 billion $\mathrm{m}^{3} /$ year or $14 \%$ of the potential demand.

In the scenarios of development of LNG and LPG supply systems the conditions for households are unfavorable due to the non-competitive gas cost.

Hence, the construction of the export gas pipeline with a large diameter or the regional gas pipeline from the Kovykta GCF lays the real groundwork for using natural gas in the Baikal region.

In the other scenarios the natural gas will be non-competitive compared to the used energy sources or the gas supply system will be non-profitable.

\section{Acknowledgements}

Research was partially supported by the RFBR grants No. 17-48-380002, 18-51094006.

\section{References}

1. Eastern vector of Russia's energy strategy: current state, look into the future. Ed. by N.I. Voropai, B.G. Saneev. Novosibirsk: Academic Publishing House "Geo", 368 p. (2011) 
2. Fuel and energy complex of the Irkutsk region. Current state, development prospects. Ed. by B.G. Saneev, P.A. Voronin. Moscow: Publishing House "Energia", 230 p. (2013)

3. Energy sector of the Baikal region: current state, prospects, development strategy. Ed. by B.G. Saneev. Novosibirsk: Academic Publishing House "Geo", 176 p. (2015)

4. A.K. Izhbuldin, L.A. Platonov. Analysis of routes for Russian piped gas supplies to China. Energy of Russia in XXI century. Innovative development and management. Collected papers of the All-Russian Conference "Energy of Russia in XXI century. Innovative development and management", September 1-3, 2015, Irkutsk, Russia. Irkutsk: ISEM SO RAN, 591 p. (2015). ISBN 978-5-93908-138-2. P 156-161.

5. I.Yu. Ivanova, T.F. Tuguzova, A.K. Izhbuldin. Comparative effectiveness of natural gas utilization for heat supply to consumers of the Baikal natural area. Energy: management, quality and effectiveness of energy resources utilization. Collected works of the $8^{\text {th }}$ International Scientific-Technical Conference. Blagoveshchensk: Publishing House PE “A.A. Sazhinov”, 578 p. (pp. 330-334) (2015) 